\title{
PKM Pelatihan Penggunaan Aplikasi Bot Whatsapp Untuk Pelaporan Pelanggaran Siswa SMP Nurul Jadid
}

Maulidiansyah ${ }^{1}$, Muhammad Zulfa Zainul Muhsin'², Taufiq Hidayatullah ${ }^{3}$, Nurul Faizin ${ }^{4}$, Nurul Hidayah ${ }^{5}$, Rizki Anwar ${ }^{6}$, Mukhlas Adi Putra7, Muhammad Abdullah Aziz ${ }^{8}$

1,2,3 Universitas Nurul Jadid, Indonesia \{maulid@unuja.ac.id¹, zainulmuhsin46@gmail.com², fiqkyu310301@gmail.com³, nurulfaizin034@gmail.com ${ }^{4}$, nhidayah2143@gmail.com ${ }^{5}$, aanblendez6@gmail.com ${ }^{6}$, madip@gmail.com7, aziz23052000@gmail.com\}

\begin{tabular}{|c|c|}
\hline Submission: $20 / 09$ & Received: 31/12/2021 \\
\hline $\begin{array}{l}\text { Keywords: } \\
\text { Student Violation, } \\
\text { Training, Bot } \\
\text { Whatsapp }\end{array}$ & $\begin{array}{l}\text { Abstract. Student violations are one of the school's policies that aim } \\
\text { to reduce the level of violations committed by students. Each type } \\
\text { of violation has a different weight or value according to the level of } \\
\text { the size of the violation. In this service, it is proposed to make a } \\
\text { Training on the Use of the Whatsapp Bot Application for Reporting } \\
\text { Violations of Nurul Jadid Middle School Students. The aim is to } \\
\text { inform parents that the student concerned has committed a } \\
\text { violation and to make it easier for the principal in monitoring and } \\
\text { evaluating student violations. The results of this service are in the } \\
\text { form of training on the use of the Whatsapp Bot Application for } \\
\text { student violations and in the form of information on student } \\
\text { violations and types of violations that are often violated. }\end{array}$ \\
\hline
\end{tabular}

Katakunci: Pelanggaran Siswa, Pelatihan, Whatsapp Bot

\begin{abstract}
Abstrak. Pelanggaran siswa merupakan salah satu kebijakan sekolah yang bertujuan untuk mengurangi tingkat pelanggaran yang dilakukan oleh siswa. Masing-masing jenis pelanggaran mempunyai bobot atau nilai yang berbeda sesuai dengan tingkat besar kecilnya pelanggaran. Pada pengabdian diusulkan untuk membuat sebuah Pelatihan Penggunaan Aplikasi Bot Whatsapp Untuk Pelaporan Pelanggaran Siswa SMP Nurul Jadid. Tujuannya adalah untuk memberitahukan kepada orang tua siswa bahwa siswa yang berkaitan telah melakukan pelanggaran serta mempermudah kepala sekolah dalam memonitoring dan mengevaluasi pelanggaran siswa. Hasil dari pengabdian ini yaitu berupa Pelatihan Penggunaan Aplikasi Bot Whatsapp pelanggaran siswa serta berupa informasi pelanggaran siswa dan jenis pelanggaran yang sering dilanggar.
\end{abstract}




\section{Pendahuluan}

Setiap sekolah pasti mempunyai aturan atau tata tertib yang wajib ditaati oleh seluruh siswa sekolah tersebut. Jika aturan atau tata tertib tersebut dilanggar maka terdapat sanksi yang sesuai dengan apa yang telah dilanggar.

SMP Nurul Jadid Paiton memiliki aturan dengan sistem negatif point pelanggaran siswa. Jika siswa melanggar aturan yang telah ditetapkan maka siswa tersebut akan mendapatkan negatif point. Negatif point tersebut akan dicatat oleh bagian kesiswaan dalam buku besar, kemudian hasil pencatatan tersebut diserahkan kepada guru BP/BK. Guru BP/BK menentukan sanksi sesuai jumlah point dan sesuai kebijakan sekolah dengan berbagai pertimbangan.

Dalam pelatihan ini, software yang akan digunakan adalah java dan aplikasi Bot Whatsapp. Tujuan pelatihan ini adalah:

a. Melatih para guru SMP Nurul Jadid untuk menginstall JRE.

b. Melatih untuk menjalankan aplikasi Bot Whatsapp dengan benar.

Manfaat dari aplikasi Bot Whatsapp adalah:

a. Membantu menginformasikan pelanggaran siswa kepada orang tua siswa.

b. Dan para guru SMP Nurul Jadid dapat menginformasikannya kepada orang tua dengan mudah.

\section{Metode}

Metode yang digunakan pada pengabdian ini menggunakan pendekatan terstruktur yaitu waterfall.

Tahapan yang dilakukan untuk memperoleh data yang dibutuhkan dalam proses merancang dan membangun Pengaplikasian Sistem Informasi Pelanggaran Siswa Kepada Orang Tua/Wali di SMP Nurul Jadid Paiton ini yaitu: 
1) Studi lapangan (field research)

a. Observasi

Metode ini melakukan pengamatan langsung terhadap kegiatan yang sedang berjalan. Pada proses ini, observasi dilakukan dengan datang langsung ke SMP Nurul Jadid Paiton dan mengamati kegiatan yang berhubungan dengan kebutuhan instansi yang akan dimasukan ke dalam program.

b. Wawancara

Wawancara merupakan metode pengumpulan data atau fakta yang penting dan banyak dilakukan dengan cara melakukan tanya jawab secara langsung kepada narasumber. Dalam pengabdian ini wawancara dilakukan kepada wakil kepala sekolah kesiswaan SMP Nurul Jadid Paiton sebagai narasumber yang akan memberikan informasi untuk melengkapi data.

2) Studi kepustakaan (library research)

Metode ini dilakukan dengan mengumpulkan data-data dari bahan tertulis dari berbagai sumber seperti jurnal, buku ataupun internet yang berhubungan dengan masalah yang dibahas untuk memperoleh kajian teoritis.

\section{Hasil}

A. Penyampaian Materi

Materi yang disampaikan pada pelatihan ini terdiri dari:

1. Instalasi software JRE.

File software sudah dibagikan pada awal pelatihan. Para Guru melalukan copy-paste pada 782omputer masing-masing. Menjalankan program dengan cara megklik next dan setuju pada ketentuan yang disyaratkan (Gambar 1). Selanjutnya melakukan proses penginstalan sesuai arahan. Setelah selesai akan muncul seperti pada (Gambar 3), selanjutnya klik Finish. JRE telah siap digunakan. 


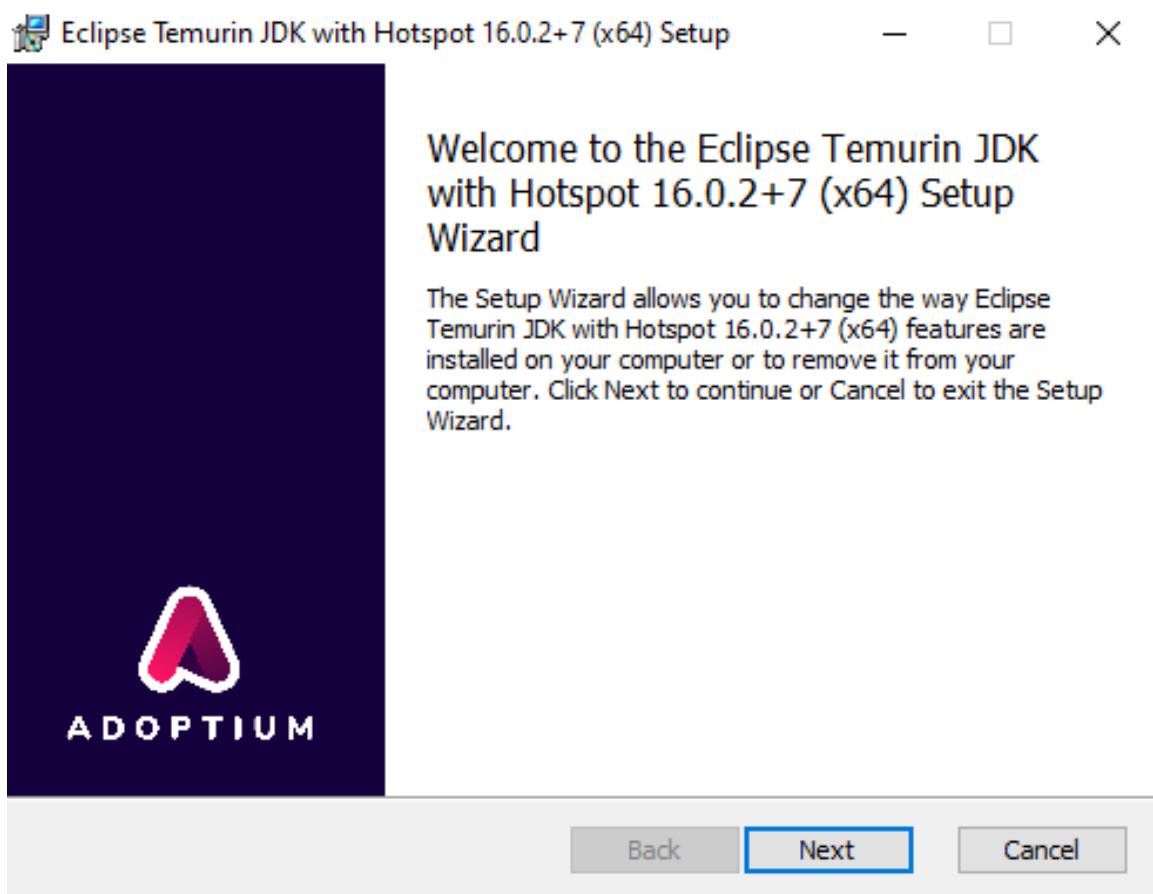

Gambar 1 Menjalankan JRE Setup.

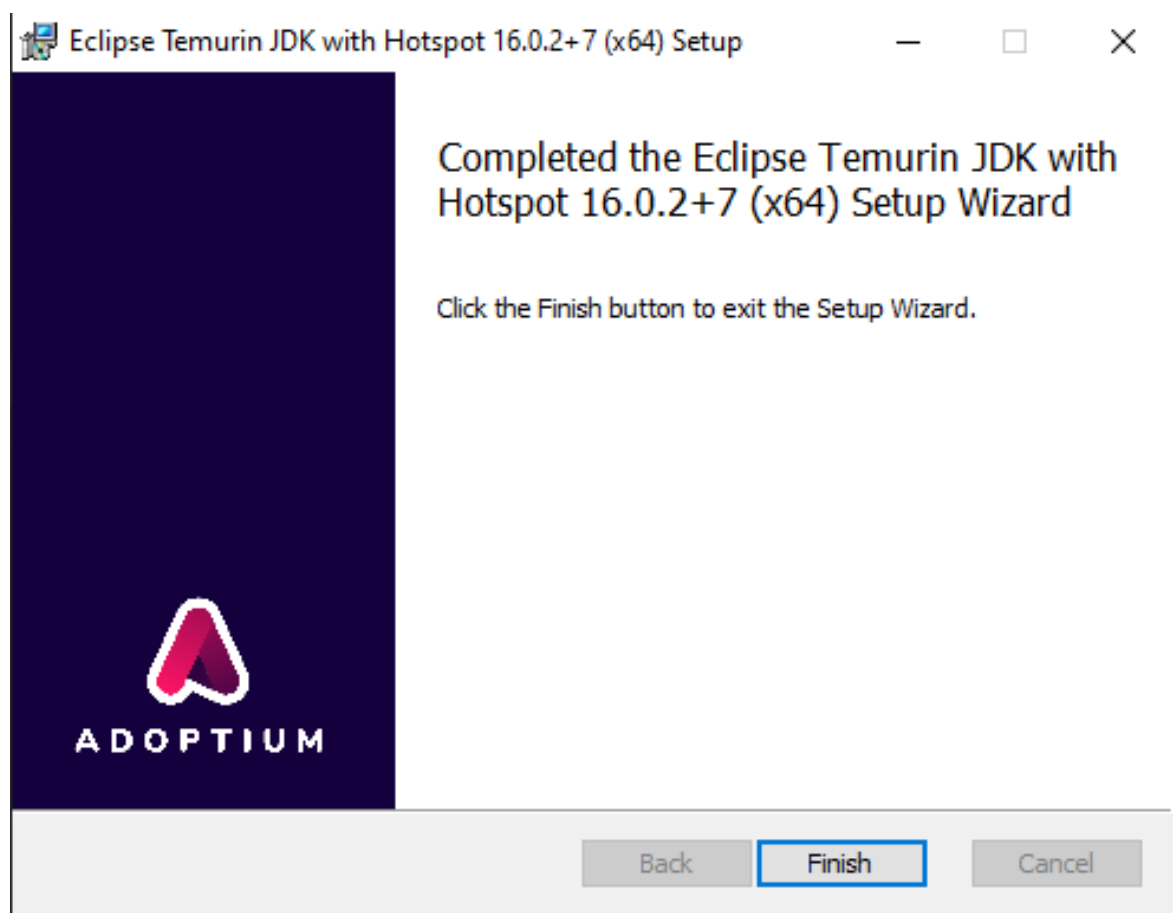

Gambar 2 Tampilan setelah selesai setup JRE 
2. Dan Menjalankan Aplikasi Bot Whatsapp

Untuk menjalan aplikasi Bot Whatsapp dipelukan dulu untuk menginput nama siswa, jenis pelanggaran, no whatsap di file yang sudah diberikan.

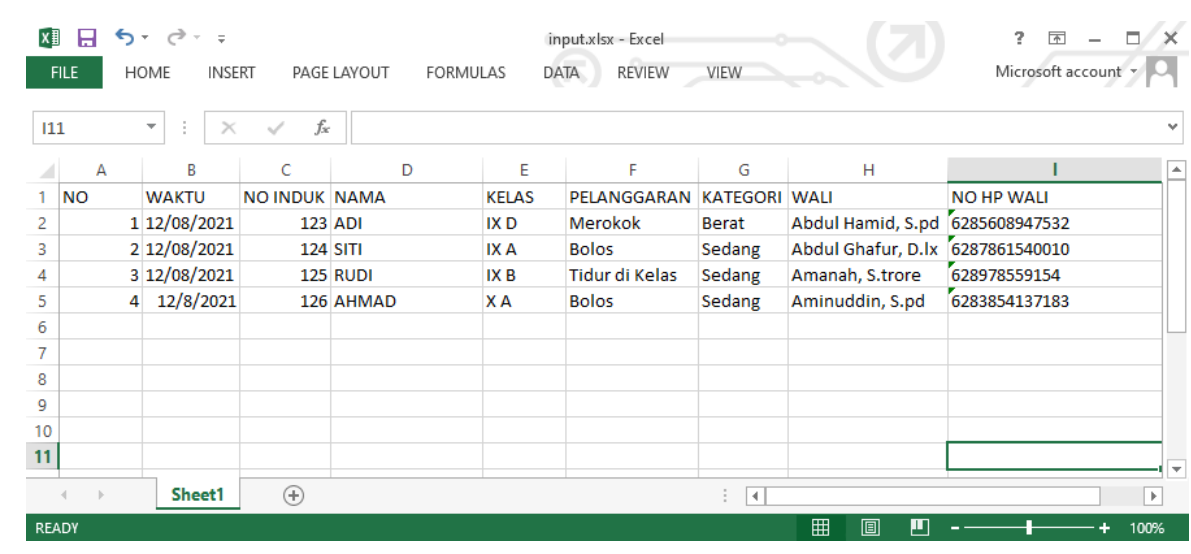

Gambar 3 Proses Penginputan.

Selanjutnya tinggal buka aplikasi Bot Whatsappnya. Tampilannya seperti pada Gambar 4.

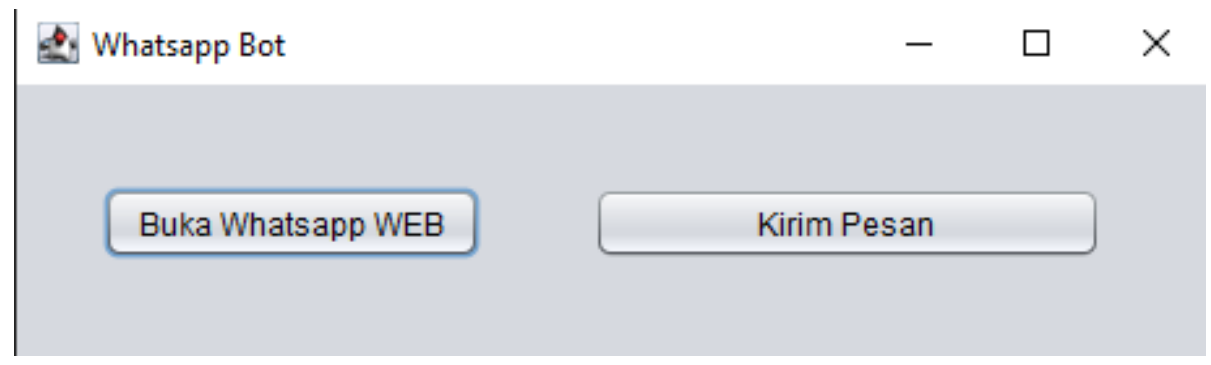

Gambar 4 Tampilan Bot Whatsapp

Langkah selanjutnya pilih "Buka Whatsapp Web", dengan otomatis akan ke dalam web whatsapp, seperti pada Gambar 5. 


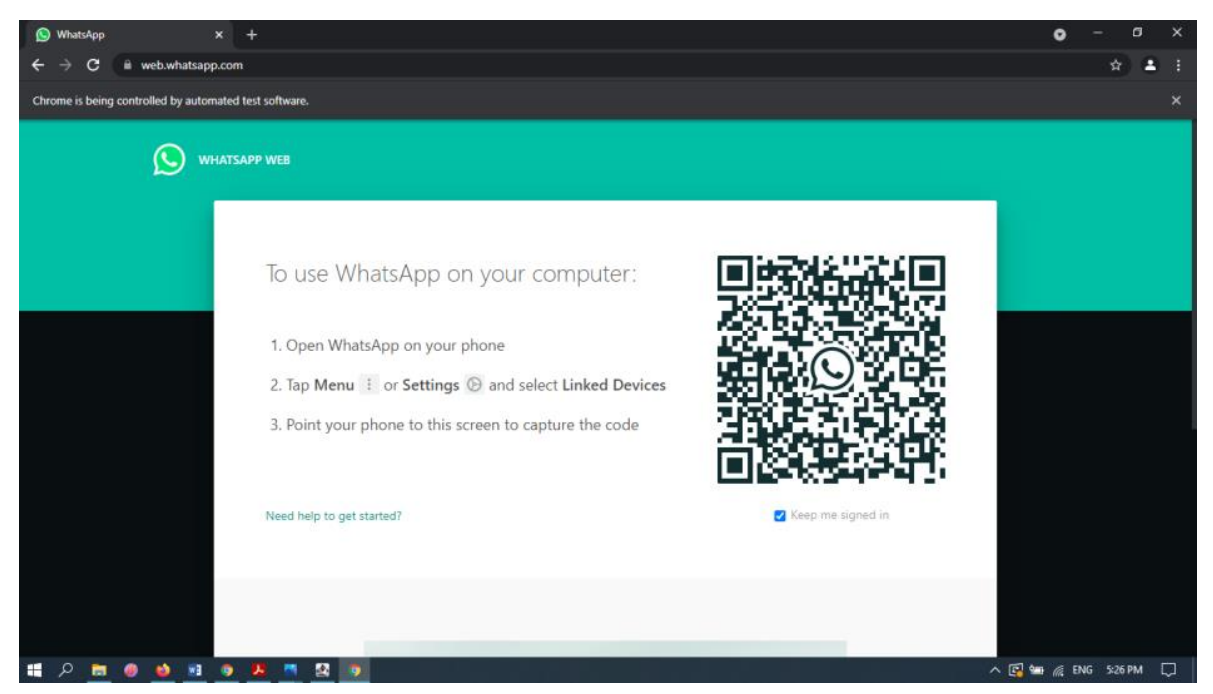

Gambar 5 Web Whatsapp

Langkah selanjutnya tinggal scan kode QR-nya menggunakan aplikasi Whatapp android untuk menghubungkan nomor whatsapp. Dan untuk pengiriman laporan pelanggaran tinggal pilih "Kirim Pesan" pada Gambar 6.

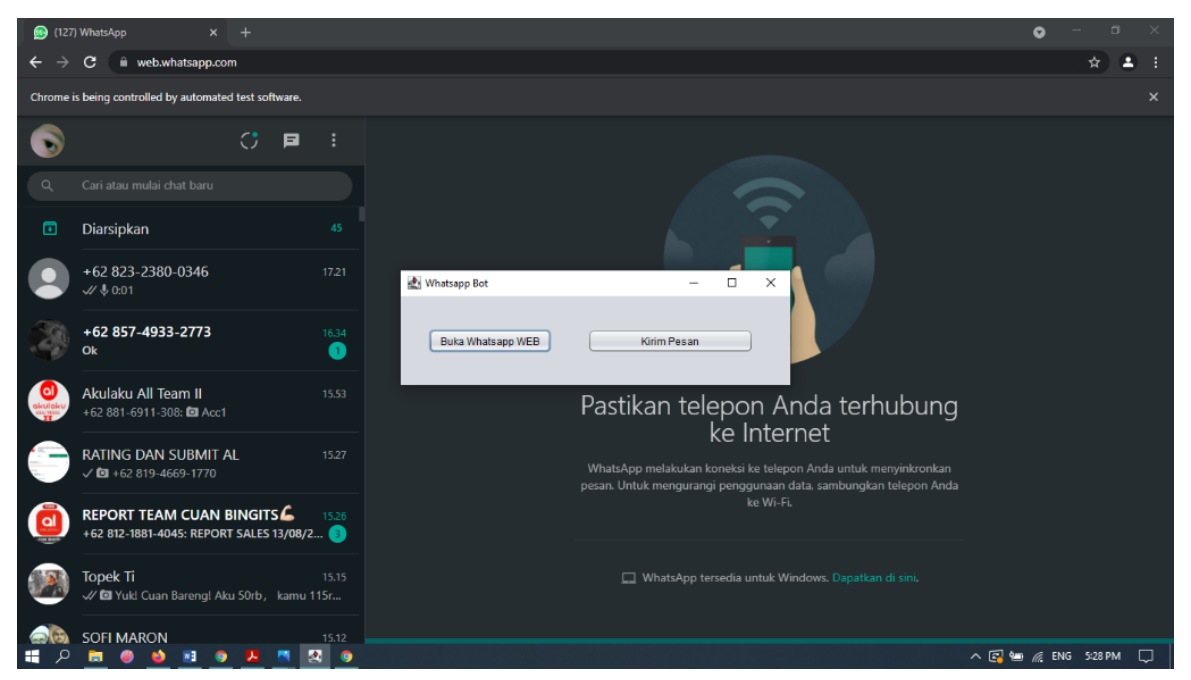

Gambar 6 Pengiriman Pesan

Selanjutnya secara otomatis pesan akan terkirim kepada nomor whatsapp yang telah dituju seperti yang ada pada Gambar 7. 


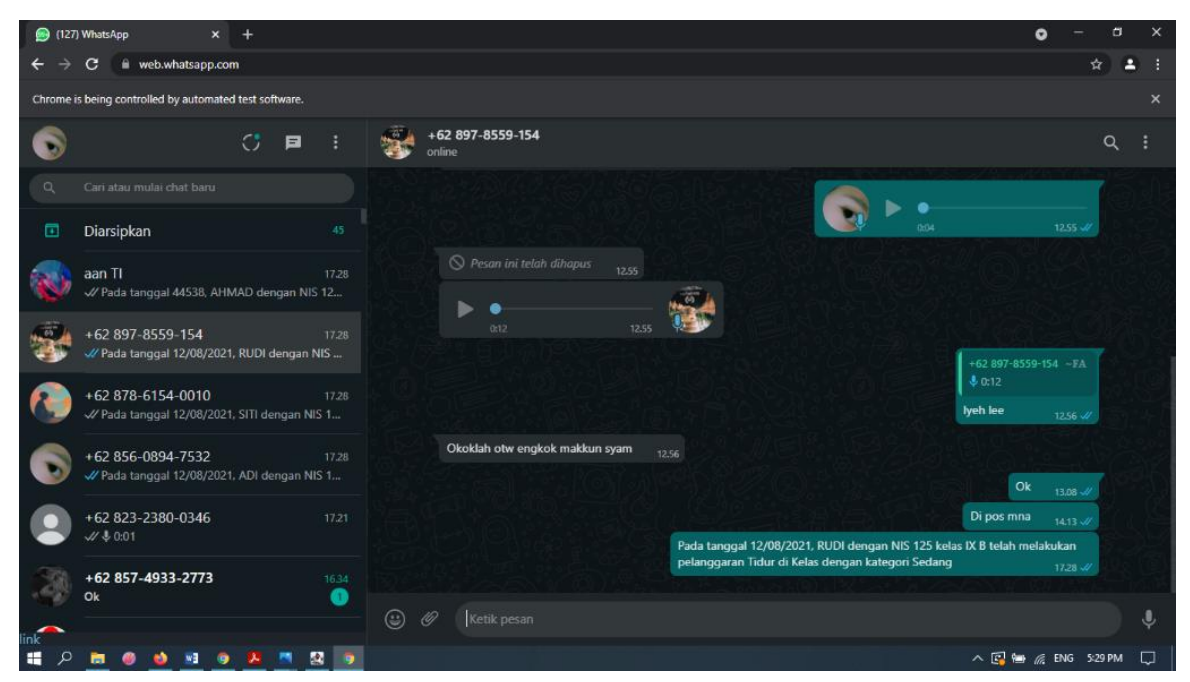

Gambar 7

\section{Pembahasan}

A. Kelebihan

Kelebihan dari Pengaplikasian Sistem Informasi Pelanggaran Siswa Kepada Orang Tua/Wali Siswa yang dibangun adalah:

1) Tersedianya fasilitas Informasi Pelanggaran siswa kepada orang tua/wali siswa.

2) Tersedianya fasilitas Informasi pelanggaran sehingga dapat memonitoring jenis pelanggaran yang sering dilanggar.

B. Kekurangan

Kekurangan dari implementasi dashboard pada sistem informasi negatif point pelanggaran siswa yang dibangun adalah:

1) Tidak terdapat notifikasi atau pemberitahuan terhadap aktivitas yang terjadi.

2) Tidak terdapat fitur pencarian untuk menampilkan siswa yang sering melakukan pelanggaran. 


\section{Kesimpulan}

A. Kesimpulan

Berdasarkan hasil pengabdian, maka dapat disimpulkan bahwa:

1. Telah berhasil dilaksanakannya Pelatihan Penggunaan Aplikasi Bot Whatsapp Untuk Pelaporan Pelanggaran Siswa SMP Nurul Jadid.

2. Terwujudnya Pengaplikasian Sistem Informasi Pelanggaran Siswa Kepada Orang Tua/Wali Siswa sebagai alat untuk memonitoring pelanggaran siswa.

B. Saran

Berdasarkan kekurangan yang terdapat pada implementasi dashboard pada sistem informasi negatif point pelanggaran siswa, maka disarankan untuk:

1. Terdapat notifikasi atau pemberitahuan terhadap aktivitas yang terjadi.

2. Menyediakan fitur pencarian untuk menampilkan menampilkan siswa yang sering melakukan pelanggaran.

\section{Pengakuan}

Kami dari Pembuat Jurnal Pengabdian Pengaplikasian Sistem Informasi Pelanggaran Siswa Kepada Orang Tua/Wali mengucapkan terimakasih yang sebesar-besarnya kepada Maulidiansyah, M.Kom. dan SMP Nurul Jadid Paiton yang membantu menjadi Peer-Reviewers dalam penerbitan Volume 1 Nomor 1 Tahun 2021.

\section{Referensi}

Rohayati, mita. 2014. Membangun Sistem Informasi Monitoring Data Inventory di Vio Hotel Indonesia. Jurnal.H. M. Arifin. 1994. IImu Pendidikan Islam. Jakarta: Bumi Putra.

Pressman, R. S. 2010. Software Engineering: A Practitioner's Appoarch 7th Edition. New York: McGraw-Hill.

Dewi, dkk. 2012. Implementasi Dashboard Monitoring Sistem Pada Web Aplikasi Absensi Guru (Study Kasus SMK Al Amanah). Jurnal.Purwanto, M. Ngalim. 1994. Psikologi Pendidikan. Remaja Rosdakarya. Bandung. 
Yarliani, Ikta \& Fadli, Mukhtar. Penyebab Perilaku Tidak Disiplin pada Siswa .Jurnal Ta'lim Muta'allim, Vol. II Nomor 4 Tahun 2012. 